\title{
INTRODUCTORY STUDENTS' ATTITUDES AND APPROACHES TO PHYSICS PROBLEM SOLVING: MAJOR, ACHIEVEMENT LEVEL AND GENDER DIFFERENCES
}

\author{
Nuri Balta ${ }^{1}$ (D), Mervi A. Asikainen ${ }^{2}$ (D) \\ ${ }^{1}$ University of International Business, Almaty-Kazakhstan (Kazakhstan) \\ ${ }^{2}$ University of Eastern Finland, Joensuu, Finland \& Western Norway University of Applied Sciences (Norway) \\ baltanurigmail.com,mervi.asikainen@uef.fi
}

Received January 2019

Accepted April 2019

\section{Abstract}

Students' attitudes and approaches to problem solving are claimed to be related to their ways they learn physics and to their success in solving physics problems. In this study, the Attitudes and Approaches to Problem Solving (AAPS) survey was used to reveal Turkish introductory university students' attitudes and approaches to physics problem solving. The data were collected from 175 students, in the spring semester of 2015-2016 academic year, from an introductory physics course at a university in the Black See Region of Turkey. The analysis of the data was conducted by grouping the data by major, achievement level, and gender. They were no statistically significant differences between the averages of civil engineering and molecular biology majors, and between male and female students. However, we obtained a small sample correlation between students' attitudes and exam grades that suggests high achievers' attitudes and approaches to physics problems are more expert-like than the attitudes and approaches of low achievers. Implications for problem solving strategies and directions for further research are discussed.

Keywords - Physics education, Problem solving in physics, AAPS survey, Attitudes, Gender.

\section{To cite this article:}

Balta, N., \& Asikainen, M.A. (2019). Introductory students' attitudes and approaches to physics problem solving: Major, achievement level and gender differences. Journal of Technology and Science Education, 9(3), 378-387. https://doi.org/10.3926/jotse.666

\section{Introduction}

One of the aims of physics teaching is to educate fluent problem-solvers, who are capable of transfer their knowledge and skills in real world situations (Walsh, Horward \& Bowe, 2007). It is also important that students are able to use their knowledge in analysis of new physics situations, where adoption of good problem-solving skills is in a vital role (Hegde \& Meera, 2012).

Becoming a fluent problem-solver in physics is demanding because it requires effective understanding of physics, combining different ideas and concepts of coherently, and good general problem-solving skills (Hegde \& Meera, 2012). To discover what fluency in problem-solving is about, experts and novices have been studied. According to Reif and Heller (1982), the main difference is that experts reorganize the 
problem and often use qualitative arguments for problem solving before its mathematical treatment. Novices, in turn, rush for the mathematical equations and run soon into trouble (Reif \& Heller, 1982; Walsh et al., 2007).

During physics education, novices are supposed to develop an organized knowledge structure, from which they can effectively retrieve necessary information (Sabella \& Redish, 2007). However, it has been observed that traditional use of problem solving in physics teaching does not support well students' conceptual understanding of physics (Kim \& Pak, 2002). On the other hand, it has been observed that if students' conceptual framework is weakly connected to the physical principles, it can cause difficulties to problem solving (Hedge \& Meera, 2012).

Walsh et al. (2007) examined introductory college students' qualitative problem-solving strategies. They found that students' strategies could be categorized into four separate categories: scientific approach, plug-and-chug, memory-based approach, and no clear approach. Most of the students applied the plug-and-chug approach: they identified the variables of the given problem and sought suitable formula based on this information instead of a holistic analysis of the physics situation, which often leads to confronting difficulties. This is in line with the observation of Bing and Redish (2009): students might be able to solve quantitative problems by substituting values in algorithmic equations, but they do not necessarily develop skills to transfer their understanding and solving more complex problems. Therefore, students do not think like physicists or physics experts.

It has been observed that students' problem solving in physics can be supported by introducing explicit problem solving strategies for them. The problem solving strategy by Reif, Larkin, and Brackett (1976) consists of four main steps: description of the problem, planning a solution, implementation of the plan, and checking the steps and the result. By introducing this kind of procedure to students, they are guided to examine a problem before rushing to calculate and to check the calculated answer. According to the researchers, this strategy works even with more complex problems but then it has to be recursive and include an exploration phase to ensure successful planning.

Gök and Silay (2010) defined problem solving by means of four steps. In their model, first comes the most important step, understanding. It means that a student has to identify and understand the problem, both qualitatively and quantitatively. The second step, planning, follows. The student has to describe the problem with a diagram or a sketch, name the needed mathematical quantities, and represent the problem with concepts and principles. Solving the problem is the third step. According to Gök and Silay, students use their qualitative understanding to construct a quantitative solution. It is also possible that the problem needs to be divided as sub problems. The last step is checking the solution to find out if it is correct.

Gök and Silay (2010) have noticed that teaching of the problem-solving using strategic steps in cooperative groups affects students' physics achievements. On contrary, the results of conventional student group showed that for instance, solving problems individually and using a solution manual in problem solving hinder student learning. Teaching problem solving strategies also effects on students' attitudes on problems solving (Gök \& Silay, 2010). Key factors in this positive change are systematic application of the problem-solving strategy, discussion with peer students, belaboring the used methods, student excitement, and encouraging and helping other students. Negatively affecting factors in conventional teaching group were ongoing assessment of students, teacher centered instruction, shortage of liability, and avoidance of encouraging and helping other students. They also noticed that students of the cooperative group developed a positive attitude toward problem solving in physics.

Byun \& Lee (2014) noted that the amount of physics problems solved is not correlated with the students' academic achievement or conceptual understanding. Instead, structured problem-solving and learning strategies effects on students' understanding (Gaigher, Rogan \& Braun, 2007).

Van MerriëNboer (2013), approaches problem solving from a more general perspective and discusses problem solving as a goal, a method, and a skill. 
As a goal, problem solving should not be limited to well-structured problem solving but be extended to real-life problem solving. As a method, problem solving has clear limitations for novice learners; providing ample support to learners is of utmost importance for helping them to develop problem-solving skills. As a skill, problem solving should not be seen as something that only occurs in the early phases of a process of expertise development but as a process that develops in parallel in System 1 and System 2. (Van MerriëNboer, 2013: page 153)

Some amount of research has been conducted to examine the effect of problem solvers' gender on problem solving (e.g. Balta, Mason \& Singh, 2016; Duran, 2016; Gallagher, De Lisi, Holst, McGillicuddy-De Lisi, Morely \& Cahalan, 2000; Sirait, Sutrisno, Balta \& Mason, 2017). However, there is no clear evidence that either of the genders would be better in problem solving than the other, therefore, more research work is needed. Moreover, comparing students' problem solving from different majors in science is of great importance because they take various courses which generally include different types of problem solving sections. Which in turn may affect their attitudes and approaches to problem solving. Our results will contribute to the literature and helps to fulfil this research gap.

The present study used the instrument Attitudes and Approaches to Problem Solving (AAPS) (Mason \& Singh, 2010) to assess the Turkish university students' attitudes and approaches to problem solving in physics. The aim was to find out the effect of students' major, achievement level, and gender on their problem-solving attitudes and approaches in physics. In addition, correlation with students' achievement level was examined.

The main research question for this study are:

1. What are the attitudes and approaches of university students to problem solving in physics?

The sub-questions are as follows:

1.1. Do male and female students differ in their attitudes and approaches to problem solving?

1.2. Do students in different majors differ in their attitudes and approaches to problem solving?

1.3. Do high and low achievers differ in their attitudes and approaches to problem solving?

\section{Method}

\subsection{Participants}

The data were collected in the second semester of a two-semester university introductory physics courses at a university in the Black Sea Region of Turkey. The courses include three hours of lecture a week including a traditional laboratory. The data were collected from two algebra-based physics courses for civil engineering and molecular biology majors at their first year at the university. These were the only groups having physics courses. Students were taking the course, electricity and magnetism, because it was required for their major. There were 120 students in civil engineering and 55 students in molecular biology major. The gender distribution was $73 \%$ male, $25 \%$ female where $2 \%$ of the students did not specify their gender. All these students were enrolled to the aforementioned university after passing through the national university entrance exam at the end of the high school. Each university has an acceptance score which depends on the quality of the education and on the selection rate by the students. In this university the molecular biology department had a higher acceptance score than the civil engineering major.

In Turkey, except the vocational high schools and several other types of schools, all high schools generally have the same national curriculum in all subjects. Physics course is compulsory for all students at the ninth and tenth grades. In these two grades, general easy physics concepts are included in the curriculum. After the tenth grade, students who prefer social sciences will not take physics course. On the other hand, students who intend to take natural sciences at the universities will take physics courses both in the eleventh and twelfth grades. 
Physics courses at the high school are generally conducted traditionally and science demonstrations are more popular than lab activates among physics teachers. However, because of the university entrance exam, teachers, students and parents (even the administrators) prefer problem solving during lessons.

These two courses are generally run in parallel (same course materials, teaching techniques, and exams were used in both courses), although the students from molecular biology major scored higher than the civil engineering major in the national university entrance exam. The lectures for both classes were all designed and given by the first author. Lectures for both classes involved chalkboard and PPT presentations and student engagement via Socrative response system (Balta, Perera-Rodríguez \& Hervás-Gómez, 2018). Students generally worked in groups on the problems, respond via Socrative response systems, and receive some feedback from the lecturer. Homework feature problems which are distinct but usually similar to problems solved during the lectures. Doing homework is mandatory and solutions for homework assignments are provided. The difficult problems in homework sets, as indicated by students, are to be solved for them. Laboratories for both courses are practically identical and only two lab sections are conducted during the semester.

\subsection{Instrument}

The data for this study were collected through use of the AAPS survey developed by Mason and Singh (2010) and translated to Turkish by Balta, Mason, and Singh (2016). The original AAPS was administered to a wide-range of students and physics faculty in USA while Turkish version of AAPS was developed through 528 high schools and university students. AAPS is an inventory of 33 Likert type items. The items of AAPS are in the form of statements that one could agree or disagree with on a scale of 1 (strongly agree) to 5 (strongly disagree) with 3 signifying a neutral response. The items are worded such that while for 24 of them, "strongly agree" and "agree" are favorable responses, for nine items "strongly disagree" and "disagree" are favorable responses (expert-like responses). For instance, the favorable answers for the first item (If I'm not sure about the right way to start a problem, I'm stuck unless I go to see the teacher/TA or someone else for help) are strongly disagree, and disagree. On the other hand, the favorable responses for the second item (When solving physics problems, I often make approximations about the physical world) are strongly agree and agree. Namely, if students choose strongly disagree or disagree for the first item, and choose strongly agree or agree for the second item their responses would be expert-like. The internal consistency of the survey, Cronbach's alpha (Gliem \& Gliem, 2003) was calculated as .82 by Mason and Singh (2016), and calculated as .85 by Balta, Mason, and Singh (2016).

In order to assess students for their success in the final exam a test that consisted of five open ended problems was given to students. The exam questions were gathered from Serway (1996). This book has colored the problem numbers to indicate if it is an easy (black), moderate (blue) or difficult (red) problem. All problems given in the exam were at moderate difficulty level. These were also the problems which students conducted mathematical operations to reach a solution. A typical exam question is as follows:

A coil formed by wrapping 50 turns of wire in the shape of a square is positioned in a magnetic field so that the normal to the plane of the coil makes an angle of $30.0^{\circ}$ with the direction of the field. When the magnetic field is increased uniformly from $200 \mathrm{mT}$ to $600 \mathrm{mT}$ in $0.400 \mathrm{~s}$, an emf of magnitude $80.0 \mathrm{mV}$ is induced in the coil. What is the total length of the wire? (Serway, 1996: page: 1004).

\subsection{Data Collection and Data Analysis}

Data collection was carried out by the researchers at the end of second semester of 2015-2016 academic year. All students in the participating classrooms took the test before the final exam, which lasted approximately for 30 minutes. The objectives of the scale were explained to the participants and they were assured that the results would be confidential.

Descriptive statistics (mean and standard deviation) were calculated for the items. The internal consistency of the scales was calculated using Cronbach's alpha (Gliem \& Gliem, 2003). In order to establish 
significant differences between male and female, and between the two majors the student t-test (Gravetter \& Wallnau, 2016) was carried out in independent samples when the normality assumption was met. The variance homogeneity assumption was tested using the Levene's test (Gravetter \& Wallnau, 2016).

It is hypothesized that students having good exam grades are more likely to develop more positive attitudes and approaches to problem solving while students having low exam grades are likely to have low levels of attitudes. This hypothesis is based on the fact that there is a relation between students' achievements and attitudes against the problem solving (Craker, 2006; Mohd \& Mahmood, 2011). Pearson correlation (Bishara \& Hittner, 2012) was conducted for AAPS scores and exam grades to explore the extent to which this is true for this cohort of students.

A statistical significance of 0.05 was assumed. The detected missing data for each groups were less than $5 \%$. The analyses were carried out with SPSS version 23.

\section{Results}

Results are presented addressing four research goals: (1) measure students' attitudes and approaches to problem solving; (2) investigate the extent to which male and female students differ in their attitudes; (3) explore the extent to which civil engineering and molecular biology major students differ in their attitudes; (4) test whether there is a relation between students' achievement level and their attitude on problemsolving.

\subsection{Analysis by Total Mean Score}

The total mean score determined from AAPS was 3.33 points $(\mathrm{SD}=0.52)$, on a scale from 1 to 5 , with 1 being the most negative attitude toward problem solving and 5 the most positive. Of the 33 items that comprise the instrument, the one with the highest mean is if I realize that my answer to a physics problem is not reasonable, I trace back my solution to see where I went wrong $(\mathrm{M}=3.97 ; \mathrm{SD}=0.90)$, while the one with the lowest is physics involves many equations each of which applies primarily to a specific situation $(\mathrm{M}=1.98 ; \mathrm{SD}=0.93)$.

The total internal consistency of the AAPS was 0.832 . We also examined what the value of Cronbach's alpha (Gliem \& Gliem, 2003) would be if a particular item was deleted from the scale. We found that removal of any question, except questions 1, 8, 16, 23 and 30, would result in a lower Cronbach's alpha. Since the removal of these four questions would lead to a small improvement (from 0.834 to 0.841 ) in Cronbach's alpha, we did not get rid of them.

\subsection{Analysis by Student Gender}

At the whole-scale level, with mean and standard deviations of $\mathrm{M}_{\mathrm{female}}=3.34, \mathrm{SD}_{\mathrm{female}}=0.31$, and $\mathrm{M}_{\text {male }}=3.24$, $\mathrm{SD}_{\text {female }}=0.36$, no significant differences are observed between male and female students $(\mathrm{t}(169)=1.68$, $\mathrm{p}=0.94$ ). The analysis of the differences by item according to student gender shows that, of the 33 items that comprise the AAPS, only 7 displayed statistically significant differences between the genders $(p<.05), 6$ of which $(16,19,21,24,28,29)$ are favorable to women and only one (10) is favorable to men. In other words, male students were more likely to reflect upon physics principles that may apply and see if they yield a reasonable solution when not sure about the approach (item 10), and female students were more likely to use their gut feeling to answer conceptual questions rather than invoking physics principle (item 16), they use different approaches to answer a multiple-choice or a corresponding free response question (item 19), after they apply the same physics principle to many situations, they should be able to apply it in other situations (item 21), they like to think through a difficult physics problem with a peer when solving introductory physics problem (item 24), they try different approaches if one approach does not work (item 28), and if they realize that their answer to a physics problem is not reasonable, they trace back their solution to see where they went wrong (item 29).

The descriptive statistics for these items are shown in Table 1 and as seen, only in item 10 the mean of males (3.65) is higher than that of females (3.28). 


\begin{tabular}{|c|c|c|c|c|c|c|c|}
\hline Item & Response & Gender & $\mathbf{N}$ & Mean & SD & $\mathrm{t}$ & $\mathrm{p}$ \\
\hline \multirow{2}{*}{10} & \multirow{2}{*}{ Expert-like } & Female & 43 & 3.28 & 0.88 & \multirow{2}{*}{-2.14} & \multirow{2}{*}{.034} \\
\hline & & Male & 126 & 3.65 & 1.01 & & \\
\hline \multirow{2}{*}{16} & \multirow{2}{*}{ Novice-like } & Female & 43 & 3.33 & 1.15 & \multirow{2}{*}{2.37} & \multirow{2}{*}{.019} \\
\hline & & Male & 128 & 2.84 & 1.15 & & \\
\hline \multirow{2}{*}{19} & \multirow{2}{*}{ Expert-like } & Female & 41 & 3.73 & 0.81 & \multirow{2}{*}{2.24} & \multirow{2}{*}{.027} \\
\hline & & Male & 126 & 3.37 & 1.11 & & \\
\hline \multirow{2}{*}{21} & \multirow{2}{*}{ Expert-like } & Female & 42 & 4.07 & 0.68 & \multirow{2}{*}{2.31} & \multirow{2}{*}{.023} \\
\hline & & Male & 126 & 3.75 & 1.00 & & \\
\hline \multirow{2}{*}{24} & \multirow{2}{*}{ Expert-like } & Female & 43 & 4.07 & 1.10 & \multirow{2}{*}{3.33} & \multirow{2}{*}{.001} \\
\hline & & Male & 127 & 3.42 & 1.12 & & \\
\hline \multirow{2}{*}{28} & \multirow{2}{*}{ Expert-like } & Female & 42 & 4.00 & 0.70 & \multirow{2}{*}{2.16} & \multirow{2}{*}{.033} \\
\hline & & Male & 125 & 3.70 & 1.02 & & \\
\hline \multirow{2}{*}{29} & \multirow{2}{*}{ Expert-like } & Female & 43 & 4.33 & 0.61 & \multirow{2}{*}{2.89} & \multirow{2}{*}{.004} \\
\hline & & Male & 126 & 3.89 & 0.92 & & \\
\hline
\end{tabular}

Note: The number of items are the original numbers in AAPS (Mason \& Singh, 2010)

Table 1. Descriptive statistics for items that significant differences are observed between male and female students

\subsection{Analysis by Major}

The independent sample t-test (Gravetter \& Wallnau, 2016) showed that the AAPS scores for civil engineering major $(\mathrm{M}=3.26, \mathrm{SD}=0.34)$ were not significantly higher than that of molecular biology major $(\mathrm{M}=3.25, \mathrm{SD}=0.39, \mathrm{t}(173)=0.116, \mathrm{p}=0.908)$. The analysis of the differences by items according to student major showed that, of the 33 items that comprise the AAPS, only 4 displayed significant differences between the two majors $(p<.05)$, all of which $(1,3,8,16)$ are favorable to molecular biology major. In other words, students in the molecular biology major were more likely to feel that if they are not sure about the right way to start a problem, they would be stuck unless they got help (item 1), to believe that being able to handle mathematics is the most important part of the process in solving a physics problem (item 3), to think that there is usually only one correct way to solve a given problem in physics (item 8), and to use their gut feeling to answer conceptual questions rather than invoking physics principle (item 16).

The descriptive statistics for these items are shown in Table 2 and as seen, in all items the mean of molecular biology major is higher than that of civil engineering major.

\begin{tabular}{|c|c|c|c|c|c|c|c|}
\hline Item & Response & major & $\mathbf{N}$ & Mean & SD & $\mathbf{t}$ & $\mathrm{p}$ \\
\hline \multirow{2}{*}{1} & \multirow{2}{*}{ Novice-like } & CE & 119 & 2.09 & 1.50 & \multirow{2}{*}{-2.29} & \multirow{2}{*}{.023} \\
\hline & & MB & 55 & 2.62 & 1.19 & & \\
\hline \multirow{2}{*}{3} & \multirow{2}{*}{ Novice-like } & CE & 118 & 2.81 & 1.29 & \multirow{2}{*}{-2.06} & \multirow{2}{*}{.041} \\
\hline & & MB & 55 & 3.24 & 1.26 & & \\
\hline \multirow{2}{*}{8} & \multirow[t]{2}{*}{ Novice-like } & $\mathrm{CE}$ & 120 & 3.32 & 1.23 & \multirow{2}{*}{-2.30} & \multirow{2}{*}{.023} \\
\hline & & MB & 55 & 3.76 & 1.10 & & \\
\hline \multirow{2}{*}{16} & \multirow{2}{*}{ Novice-like } & $\mathrm{CE}$ & 120 & 2.81 & 1.12 & \multirow{2}{*}{-2.99} & \multirow{2}{*}{.003} \\
\hline & & $\mathrm{MB}$ & 55 & 3.36 & 1.18 & & \\
\hline
\end{tabular}

MB: Molecular biology; CE: Civil engineering

Table 2. Descriptive statistics for items that significant differences are observed between different majors

\subsection{Analysis by AAPS Score and Exam Score: Correlation and Interaction}

To test whether there is a relation between high and low achievers' attitudes, Pearson's correlation (Bishara \& Hittner, 2012) was conducted (See Table 3). Pragmatically, Pearson's correlation coefficient is sensitive to skewed distributions and outliers, thus to check the normality of the variables we examined the 
skewness coefficients to see if they suggest whether either of the variables are skewed. It was found that the AAPS scores have positive skewness coefficient of 1.24 and exam scores have negative skewness coefficient of -0.15 . Any distribution having skewness values between -2 and +2 can be accepted as normal distribution (Field, 2009). Hence, since we do not have any concerns over the normality of the data, we continued with the correlation analysis.

We obtained a small sample correlation of 0.21 between students' attitudes and exam grades. This correlation was significant $(\mathrm{p}=0.007<0.05)$, indicating that final exam grades are positively correlated in the population of students in this study. This result suggests that high achievers' attitudes and approaches to physics problems is more positive when compared to low achievers.

The correlation between students' attitudes and exam grades for CE students was 0.17 while that of MB was 0.277 . Similarly, the same correlation was 0.334 for female and 0.146 for male students. This suggests that high achievers have more positive attitudes because females' average score (65) in the exam was higher when compared to that of male students (44).

\begin{tabular}{|c|r|r|r|r|r|}
\hline & \multicolumn{1}{|c|}{ All } & \multicolumn{1}{c|}{ CE } & \multicolumn{1}{c|}{ MB } & \multicolumn{1}{c|}{ Female } & \multicolumn{1}{c|}{ Male } \\
\hline $\mathrm{r}$ & .213 & .170 & .277 & .338 & .146 \\
\hline $\mathrm{p}$ & .007 & .070 & .066 & .033 & .117 \\
\hline $\mathrm{N}$ & 159 & 114 & 45 & 40 & 117 \\
\hline
\end{tabular}

Table 3. Pearson correlation between exam and AAPS scores across groups

\section{Discussion}

This study investigated university students' attitudes and approaches to problem solving in physics by means of Attitudes and Approaches to Problem Solving (AAPS) survey. The results showed that the students' attitudes and approaches were on average slightly positive (3.33 points of 5), which in this case means that they resembled more expert-like attitudes and approaches than novice-like ones. This result is in line with the previous studies (Balta, Mason \& Singh, 2016; Mason \& Singh, 2010, 2016; Sirait, Sutrisno, Balta \& Mason, 2017).

The results indicated that even there is no statistically significant difference between male and female students at total score level, there were statistical differences in seven items, of which six were favorable for females and one for males. Of these items, the one of males' and five of females' items indicated expert-like attitudes and approaches. This suggests that females of the sample may have demonstrate more expert-like attitudes and approaches to problem solving than the males. This result is similar to obtained in previous studies (Balta, Mason \& Singh, 2016; Duran, 2016) In addition, Selçuk, Çaliskan and Erol (2007) have observed that Turkish female physics teacher candidates have better problem solving strategies than the male candidates when measured with Problem Solving Strategy Scale. This is an interesting result that should be examined more carefully with larger sample because several studies on mathematical problem solving suggest that male are better problem solvers than females (Gallagher et al., 2000). Moreover, the study by Sirait et al. (2017) done in Indonesia showed that males were more expertlike when compared to females in terms of their attitudes and approaches in physics problem solving. One possible reason for this may be the fact that female university students in Turkey usually attend courses better, struggle more with homework assignments and accordingly better engaged with the problems and have higher grades (Personal observations).

Based on the results, there is no statistical difference between civil engineering majors and molecular biology majors. However, molecular biology majors' attitudes and approaches were more novice-like when compared to the engineering majors' attitudes and approaches. Even though the molecular biology majors' scores were higher in the university entrance exam when compared to the civil engineering majors, it does not mean that they are good in problem solving in physics and have expert-like attitudes and approaches toward it. It is generally known that students who have strong math and physics background prefer 
engineering subjects (Zavala, Dominguez, Millan \& Gonzalez, 2015). Also, during their first year, civil engineer major students had more math and engineering courses while molecular biology students had more biology and biology related lab courses.

The results concerning correlation of students' achievement measured by the exam grade and their attitudes and approaches to problem solving demonstrated that there is positive correlation between them. This means that high achievers have more expert-like attitudes and approaches to problem solving than the low achievers. According to Byun and Lee (2014), students' problem solving and learning strategies do have an effect on students' understanding. Therefore, student's more sophisticated strategies or approaches may result as better learning of physics.

The Attitudes and Approaches to Problem Solving survey (Mason \& Singh, 2010) is the last series of several surveys; Views about Science and Physics Achievement: The VASS story (Halloun, 1997), The Maryland Physics Expectation Survey (Redish, Saul \& Steinberg, 1998), Attitudes toward Problem Solving Survey (Cummings, Lockwood \& Marx, 2004), Colorado Attitudes about Science Survey (Adams, Perkins, Podolefsky, Dubson, Finkelstein \& Wieman, 2006), developed by experts. The similarity of our study's findings with earlier research imply that the Attitudes and Approaches to Problem Solving survey is a reliable survey that can safely be used to assess students' attitudes and approaches to solving physics problems.

Based on the results, two future studies are recommended. First, examining more carefully females' problem solving attitudes and approaches because there is inconsistency between the findings in literature. Second, examining physics students' attitudes and approaches to problem solving in different European and Asian countries would be valuable to find out is their interrelation a global phenomenon or dependent on cultural context.

\section{Declaration of Conflicting Interests}

The authors declared no potential conflicts of interest with respect to the research, authorship, and/or publication of this article.

\section{Funding}

The authors received no financial support for the research, authorship, and/or publication of this article.

\section{References}

Adams, W.K., Perkins, K.K., Podolefsky, N.S., Dubson, M., Finkelstein, N.D., \& Wieman, C.E. (2006). New instrument for measuring student beliefs about physics and learning physics: The Colorado learning attitudes about science survey. Physical Review Special Topics-Physics education research, 2(1), 010101. https://doi.org/10.1103/PhysRevSTPER.2.010101

Balta, N., Mason, A.J., \& Singh, C. (2016). Surveying Turkish high school and university students' attitudes and approaches to physics problem solving. Physical Review Physics Education Research, 12(1), 010129. https://doi.org/10.1103/PhysRevPhysEducRes.12.010129

Balta, N., Perera-Rodríguez, V.H., \& Hervás-Gómez, C. (2018). Using Socrative as an online homework platform to increase students' exam scores. Education and Information Technologies, 23(2), 837-850. https://doi.org/10.1007/s10639-017-9638-6

Bing, T.J., \& Redish, E.F. (2009). Analyzing problem solving using math in physics: Epistemological framing via warrants. Physical Review Special Topics-Physics Education Research, 5(2), 020108. https://doi.org/10.1103/PhysRevSTPER.5.020108 
Bishara, A.J., \& Hittner, J.B. (2012). Testing the significance of a correlation with nonnormal data: comparison of Pearson, Spearman, transformation, and resampling approaches. Psychological methods, 17(3), 399. https://doi.org/10.1037/a0028087

Byun, T. \& Lee, G. (2014). Why students still can't solve physics problems after solving over 2000 problems. American Journal of Physics, 82(9), 906-913. https://doi.org/10.1119/1.4881606

Craker, D.E. (2006). Attitudes toward science of students enrolled in introductory level science courses at UW-La Crosse. UW-L Journal of undergraduate research IX, 9, 1-6.

Cummings, K., Lockwood, S., \& Marx, J.D. (2004, September). Attitudes toward problem solving as predictors of student success. In AIP Conference Proceedings, 720(1), 133-136. AIP. https://doi.org/10.1063/1.1807272

Field, A. (2009). Discovering statistics using SPSS. London: SAGE.

Duran, M. (2016). An Academic Survey Concerning High School and University Students' Attitudes and Approaches to Problem Solving in Chemistry. International Journal of Environmental and Science Education, 11(5), 819-837. https://doi.org/10.12973/ijese.2016.407a

Gaigher, E., Rogan, J.M., \& Braun, M.W.H. (2007). Exploring the development of conceptual understanding through structured problem-solving in physics. International Journal of Science Education, 29(9), 1089-1110. https://doi.org/10.1080/09500690600930972

Gallagher, A.M., De Lisi, R., Holst, P.C., McGillicuddy-De Lisi, A.V., Morely, M., \& Cahalan, C. (2000). Gender differences in advanced mathematical problem solving. Journal of Experimental Cbild Psychology, 75(3), 165-190. https://doi.org/10.1006/jecp.1999.2532

Gliem, J.A., \& Gliem, R.R. (2003). Calculating, interpreting, and reporting Cronbach's alpha reliability coefficient for Likert-type scales. Midwest Research to Practice Conference in Adult, Continuing, and Community Education. Ohio State University, Columbus, Ohio. Available at: https://scholarworks.iupui.edu/bitstream/handle/1805/344/Gliem\%20\&\%20Gliem.pdf?s

Gravetter, F.J., \& Wallnau, L.B. (2016). Statistics for the behavioral sciences. Boston, MA: Cengage Learning.

Gök, T., \& Silay, I. (2010). The Effects of Problem Solving Strategies on Students' Achievement, Attitude and Motivation. Latin-American Journal of Physics Education, 4(1), 2.

Halloun, I. (1997, March). Views about science and physics achievement: The VASS story. In AIP conference Proceedings, 399(1), 605-614. AIP. https://doi.org/10.1063/1.53156

Hegde, B., \& Meera, B.N. (2012). How do they solve it? An insight into the learner's approach to the mechanism of physics problem solving. Physical Review Special Topics-Physics Education Research, 8(1), 010109. https://doi.org/10.1103/PhysRevSTPER.8.010109

Kim, E., \& Pak, S.J. (2002). Students do not overcome conceptual difficulties after solving 1000 traditional problems. American Journal of Physics, 70(7), 759-765. https://doi.org/10.1119/1.1484151

Mohd, N., \& Mahmood, T.F.P.T. (2011). The effects of attitude towards problem solving in mathematics achievements. Australian Journal of Basic and Applied Sciences, 5(12), 1857-1862.

Mason, A., \& Singh, C. (2010). Surveying graduate students ' attitudes and approaches to problem solving. Physical Review Special Topics - Physics Education Research, (May), 1-16.

https://doi.org/10.1103/PhysRevSTPER.6.020124

Mason, A.J. \& Singh, C. (2016). Surveying college introductory physics students' attitudes and approaches to problem solving. European Journal of Physics, 37(5), 055704. https://doi.org/10.1088/0143-

$0807 / 37 / 5 / 055704$ 
Redish, E.F., Saul, J.M., \& Steinberg, R.N. (1998). Student expectations in introductory physics. American Journal of Physics, 66(3), 212-224. https://doi.org/10.1119/1.18847

Reif, F., \& Heller, J.I. (1982). Knowledge structure and problem solving in physics. Educational Psychologist, 17, 102-127. https://doi.org/10.1080/00461528209529248

Reif, F., Larkin, J.H., \& Brackett, G.C. (1976). Teaching general learning and problem-solving skills. American Journal of Physics, 44(3), 212-217. https://doi.org/10.1119/1.10458

Sabella, M.S., \& Redish, E.F. (2007). Knowledge organization and activation in physics problem solving. American Journal of Physics, 75(11), 1017-1029. https://doi.org/10.1119/1.2746359

Selçuk, G.S., Çaliskan, S., \& Erol, M. (2007). The effects of gender and grade levels on Turkish physics teacher candidates' problem solving strategies. Journal of Turkish Science Education (TUSED), 4(1), 92-100.

Serway, R.A. (1996). Physics for Scientists and Engineers with Modern Physics (4th ed.). Saunders College Publications.

Sirait, J., Sutrisno, L., Balta, N., \& Mason, A. (2017). The Development of Questionnaire to Investigate Students' Attitudes and Approaches in Physics Problem Solving. Jurnal Pendidikan Fisika Indonesia, 13(2), 79-87. https://doi.org/10.15294/jpfi.v13i2.6592

Walsh, L.N., Howard, R.G. \& Bowe, B. (2007). Phenomenographic study of students' problem solving approaches in physics. Physical Review Special Topics - Physics Education Research, 3, 020108. https://doi.org/10.1103/PhysRevSTPER.3.020108

Van MerriëNboer, J.J.G. (2013). Perspectives on problem solving and instruction. Computers \& Education, 64, 153-160. https://doi.org/10.1016/j.compedu.2012.11.025

Zavala, G., Dominguez, A., Millan, A.C., \& Gonzalez, M. (2015). Students' perception of relevance of physics and mathematics in engineering majors. In 2015 122nd ASEE Annual Conference and Exposition. American Society for Engineering Education. https://doi.org/10.18260/p.24772

\author{
Published by OmniaScience (www.omniascience.com) \\ Journal of Technology and Science Education, 2019 (www.jotse.org)
}

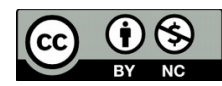

Article's contents are provided on an Attribution-Non Commercial 4.0 Creative commons International License. Readers are allowed to copy, distribute and communicate article's contents, provided the author's and JOTSE journal's names are included. It must not be used for commercial purposes. To see the complete licence contents, please visit https://creativecommons.org/licenses/by-nc/4.0/. 